\title{
Relationship between maternal hemoglobin concentration during pregnancy and neonatal birth weight in urban poor community in and around Jamshedpur, Jharkhand, India
}

\author{
Pushpa Tiwari* \\ Department of Public Health, Tata Steel Foundation, Tata Steel, Jamshedpur, Jharkhand, India \\ Received: 26 July 2021 \\ Revised: 06 September 2021 \\ Accepted: 07 September 2021 \\ *Correspondence: \\ Dr. Pushpa Tiwari, \\ E-mail: pushpa.tiwari@tatasteel.com \\ Copyright: ( $)$ the author(s), publisher and licensee Medip Academy. This is an open-access article distributed under \\ the terms of the Creative Commons Attribution Non-Commercial License, which permits unrestricted non-commercial \\ use, distribution, and reproduction in any medium, provided the original work is properly cited.
}

\begin{abstract}
Background: Anemia is a major health issue affecting both developing and developed countries worldwide. In the developing countries, poverty, gender bias and lack of education about the importance of a balanced and iron-rich diet contribute to anemia. According to WHO anemia is present when the hemoglobin percentage is less than $11 \mathrm{gm}$ per dl during pregnancy. The birth weight of an infant is the most important determinant of its chance of survival health growth and development. The prevalence of low birth weight (LBW) is higher in Asia than elsewhere. Low birth weight is a major determinant of mortality, morbidity and disability in infancy and childhood and has a long term impact on health outcomes in adult life. The purpose of this study was to assess the relationship between maternal hemoglobin concentration with neonatal birth weight.

Methods: This was a descriptive study. Details were collected from ante-natal records of women, attending 10 numbers of Maternal and Child health clinics run by Tata Steel Family Initiatives Foundation for urban poor community in and around Jamshedpur. This study was done over a period of 7 months from May 2018 to November 2018. Data was collected retrospectively after women had delivered. A sample size of 511 women was taken as a part of the survey. Results: Analysis of the data shows that anemia was associated with a significantly increase risk of low birth weight $(<2500 \mathrm{gm})$. In our study it was found that $\mathrm{Hb}$ level in $3^{\text {rd }}$ trimester had more impact on birth weight than in $1^{\text {st }}$ trimester. Conclusions: Maternal anemia was significantly associated with effect on birth weight. Effort should be directed towards awareness of women regarding prevention of anemia so that their pre pregnancy hemoglobin level is normal and babies born are of normal birth weight.
\end{abstract}

Keywords: Birth weight, Hemoglobin, Maternal, Neonatal

\section{INTRODUCTION}

Anemia is a major health issue affecting both developing and developed countries worldwide. A report of 2005 suggested that globally about 1.62 billion people are affected by anemia, which is about $24.8 \%$ of world's population. ${ }^{1}$ In the developing countries, poverty, gender bias and lack of education about the importance of a balanced and iron-rich diet contribute to anemia. The high prevalence of iron and other micronutrient deficiencies among women before and during pregnancy in developing countries is of concern and maternal anemia is still a cause of considerable perinatal mortality and morbidity. According to WHO anemia is present when the hemoglobin percentage is less than $11 \mathrm{gm}$ per dl during pregnancy. $^{2}$

The Indian Council of Medical Research has categorized anemia as per Table 1 . 
Table 1: Classification of anemia.

\begin{tabular}{|ll|}
\hline $\begin{array}{l}\text { Category (anemia } \\
\text { severity) }\end{array}$ & $\begin{array}{l}\text { Hemoglobin level } \\
(\mathrm{gm} / \mathrm{dl})\end{array}$ \\
\hline Mild & $10-10.9$ \\
\hline Moderate & $7.0-9.9$ \\
\hline Severe & $4.0-6.9$ \\
\hline Very severe & $<4.0$ \\
\hline
\end{tabular}

Most common cause of anemia during pregnancy is iron deficiency. In addition to iron deficiency other causes of anemia are megaloblastic anemia, anemia caused by acute blood loss, anemia of inflammation or malignancy, acquired hemolytic anemia, aplastic/hypo plastic anemia and other hereditary causes like thalassemia, hemoglobinopathies, and hereditary hemolytic anaemia. ${ }^{3}$ The modest fall in hemoglobin levels observed during pregnancy in healthy women not deficient in iron or folate is caused by a relatively greater expansion of plasma volume compared with the increase in hemoglobin mass and red cell volume. The disproportion between the rates at which plasma and erythrocytes are added to the maternal circulation is normally greatest during the second trimester. The resulting hemodilution results in physiological anemia of pregnancy. $^{3}$ During the puerperium, in the absence of excessive blood loss, hemoglobin concentration is not appreciably less than pre delivery. After the delivery the hemoglobin level fluctuates around the pre delivery value for a few days and then rises to the higher non pregnant level. The rate and magnitude of increase early in the puerperium is the result of the amount of hemoglobin added during pregnancy and the amount lost by blood loss at delivery and modified by a puerperal decrease in plasma volume. Effects of anemia in the baby are low birth weight and intrauterine growth retardation (this occurs because maternal anemia influences placental vascularization by altering angiogenesis during early pregnancy). ${ }^{4}$

The birth weight of an infant is the most important determinant of its chance of survival health growth and development. The prevalence of low birth weight (LBW) is higher in Asia than elsewhere. Low birth weight is a major determinant of mortality, morbidity and disability in infancy and childhood and has a long term impact on health outcomes in adult life.

Effects of anemia on mother are preeclampsia and eclampsia, abruptio placenta, preterm labor, premature rupture of membranes, precipitate labor, postpartum hemorrhage, cardiac failure in severe anemia, puerperal infection, deep vein thrombosis, and failure of lactation.

According to WHO, "babies with a weight of 2,500 grams or less should be designated as low birth-weight babies. Micronutrient deficiencies during pregnancy have shown to have serious implications on the developing fetus. Birth weight is a strong indicator not only of the mother's health and nutritional status but also of the newborn's chances for survival, growth, long-term health and development. ${ }^{6}$ The low birth weight neonates are predisposed to a number of neonatal problems like hypothermia, inability to suckle the breast, asphyxia, sepsis, infection, hypoglycemia etc. Intrauterine growth is now considered an important determinant of both short and long-term outcomes for an individual. $^{7}$

According to WHO, a newborn baby weighing less than $2500 \mathrm{gm}$ at birth is designated as low birth weight (LBW) neonate. According to UNICEF, the incidence of LBW neonates is $30 \%$ in India. ${ }^{6,7}$ Low birth weight neonates are further classified as very low birth weight (VLBW $<1500$ gm) and extremely low birth weight (ELBW $<1000 \mathrm{gm})$ infants. ${ }^{8}$ The magnitude of LBW babies in developing world is enormous. Out of a total of 22 million such infants in the world, 21 million belong to the developing countries. India's share is quite substantial: 7-10 million. Majority of LBW neonates in our country weigh between 2000-2499 gms. $^{9}$

\section{Causes of low birth weight neonates}

An adequate supply of nutrients is essential for the normal progression of healthy fetal growth and development. Studies on low birth weight and prematurity, as well as neural tube defects and other non-genetic congenital abnormalities are important cause of fetal morbidity and mortality. Several factors that can help identify nutritional risk in a pregnancy include: adolescence, anemia, abnormal pre-pregnancy weight, multiple gestation, medical illness or medication that interferes with absorption of vitamins and minerals, cigarette smoking, alcohol abuse, and low socioeconomic status. ${ }^{10}$

A study reveals that about 18 million infants died in the year 2007 because of low birth weight. Developed market economies had only 12.9 infant deaths per 1000 live births, while this no rises to 106.2 infant deaths per 1000 in the least developed countries. A study conducted at Indira Gandhi Medical College, Shimla reveals that neonatal morbidity is directly related to birth weight, as the functional immaturity of various systems result in different clinical problems. ${ }^{11}$ Children born underweight also tend to have cognitive disabilities and a lower IQ, affecting their performance in school and their job opportunities as adults. $^{12}$

The birth weights of babies whose mothers have hemoglobin less than $11 \mathrm{gm} / \mathrm{dl}$ were normal and may underscore the relative importance of plasma expansion relative to increased red cell mass in the subsequent determination of specific fetal outcomes. The importance of an adequate plasma volume expansion in allowing adequate fetal growth is attested by several investigations that showed an increased frequency of low birth weight in association with a high hematocrit. ${ }^{13,14}$

The mechanism by which this effect is mediated is unknown but may be related to the blood viscosity. 


\section{METHODS}

\section{Study design}

This was a descriptive study. Details were collected from ante-natal records of women, attending 10 nos. of maternal and child health clinics run by Tata Steel Family Initiatives Foundation for urban poor community in and around Jamshedpur. This study was done over a period of 7 months from May 2018 to November 2018. Data was collected retrospectively from the discharge slip of the hospital and investigation reports after the women had delivered and reported to the clinics of Tata Steel Family Initiatives Foundation for postnatal check-up and immunization of the baby. They were asked to bring their reports of investigations done during pregnancy and discharge slip of the hospital concerned where delivery had taken place. Women had to undergo a short interview whereby they were administered a series of questions and details were duly noted after cross-checking with the documents and records both at the center and those brought by the women for during check-up.

\section{Study setting}

The study was conducted at the 10 numbers maternal and child health clinics run free of cost under the programme of Maternal and Child Health by Tata Steel Family Initiatives Foundation for urban poor community in and around Jamshedpur city of Jharkhand state of India.

\section{Sample size}

This was an observational study. A sample size of 511 women was taken as a part of the survey.

\section{Inclusion criteria}

All women who had visited the clinic for post-natal checkup were included in the study. Women with children up to the age of less than or equal to one year were included in the study.

\section{Exclusion criteria}

Women with children above the age of 1 year were excluded from the study.

\section{Sampling}

This study was done over a period of 7 months from May 2018 to November 2018. After obtaining consent, mothers were included into the study. They were interviewed in the beginning and their antenatal record was checked. If they met the exclusion criteria, they were excluded. A total of 511 mothers were included for the study.

\section{Statistical analysis}

Statistical analysis was done on Microsoft Excel.

\section{Consent}

The details of the study were explained to the mothers during their visit to the clinics. Informed consent was taken from them before interviewing and cross checking of antenatal records.

\section{RESULTS}

In our study a strong relationship was found between maternal anemia and low birth weight babies.

Analysis of the data shows that anemia was associated with a significantly increase risk of low birth weight $(<2500$ gm).

In $1^{\text {st }}$ trimester analysis of birth weight of babies of women with normal $\mathrm{Hb}(\geq 11 \mathrm{gm} / \mathrm{dl})$ showed that $81.25 \%$ of women had given birth to babies with normal birth weight while $16.25 \%$ women had low birth weight babies (2-2.49 $\mathrm{kg}$ ) and $2.5 \%$ women had very low birth weight babies (2 $\mathrm{kg})$. In $1^{\text {st }}$ trimester analysis of birth weight of babies of women with mild anemia ( $\mathrm{Hb} 10-10.9 \mathrm{gm} / \mathrm{dl}$ ) showed that $79.65 \%$ pregnant women had given birth to babies with normal birth weight while $15.93 \%$ women had low birth weight babies and $4.42 \%$ women had very low birth weight babies. In $1^{\text {st }}$ trimester analysis of birth weight of babies of women with moderate anemia ( $\mathrm{Hb} 7-9.9 \mathrm{gm} / \mathrm{dl}$ ) showed that $77.65 \%$ pregnant women with moderate anemia had given birth to babies with normal birth weight while $18.82 \%$ women had low birth weight babies and $3.53 \%$ women had very low birth weight babies.

Table 2: Birth weight in $\mathrm{kg}\left(1^{\text {st }}\right.$ trimester $)$.

\begin{tabular}{|c|c|c|c|c|c|}
\hline $\mathrm{Hb}$ & $\geq 2.5 \mathrm{~kg}$ & $2-2.49 \mathrm{~kg}$ & $<2 \mathrm{~kg}$ & No. of pregnant women & $\%$ of pregnant women \\
\hline \multirow{2}{*}{$\geq 11 \mathrm{gm} / \mathrm{dl}$} & 65 & 13 & 2 & \multirow{2}{*}{80} & \multirow{2}{*}{28.67} \\
\hline & $81.25 \%$ & $16.25 \%$ & $2.50 \%$ & & \\
\hline \multirow{2}{*}{10 to $10.9 \mathrm{gm} / \mathrm{dl}$} & 90 & 18 & 5 & \multirow{2}{*}{113} & \multirow{2}{*}{40.50} \\
\hline & $79.65 \%$ & $15.93 \%$ & $4.42 \%$ & & \\
\hline \multirow{2}{*}{7 to $9.9 \mathrm{gm} / \mathrm{dl}$} & 66 & 16 & 3 & \multirow{2}{*}{85} & \multirow{2}{*}{30.47} \\
\hline & $77.65 \%$ & $18.82 \%$ & $3.53 \%$ & & \\
\hline \multirow[t]{2}{*}{4 to $6.9 \mathrm{gm} / \mathrm{dl}$} & 1 & 0 & 0 & \multirow{2}{*}{1} & \multirow{2}{*}{0.36} \\
\hline & $0.00 \%$ & $0.00 \%$ & $0.00 \%$ & & \\
\hline
\end{tabular}


Table 3: Birth weight in $\mathrm{kg}$ ( $2^{\text {nd }}$ trimester $)$.

\begin{tabular}{|c|c|c|c|c|c|}
\hline Hemoglobin & $\geq 2.5 \mathrm{~kg}$ & 2- $2.49 \mathrm{~kg}$ & $<2 \mathrm{~kg}$ & No. of pregnant women & $\%$ of pregnant women \\
\hline \multirow{2}{*}{$\geq 11 \mathrm{gm} / \mathrm{dl}$} & 33 & 1 & 0 & \multirow{2}{*}{34} & \multirow{2}{*}{27.64} \\
\hline & $97.06 \%$ & $2.94 \%$ & $0.00 \%$ & & \\
\hline \multirow{2}{*}{10 to $10.9 \mathrm{gm} / \mathrm{dl}$} & 38 & 5 & 4 & \multirow{2}{*}{47} & \multirow{2}{*}{38.21} \\
\hline & $80.85 \%$ & $10.64 \%$ & $8.51 \%$ & & \\
\hline \multirow{2}{*}{7 to $9.9 \mathrm{gm} / \mathrm{dl}$} & 31 & 9 & 1 & \multirow{2}{*}{41} & \multirow{2}{*}{33.33} \\
\hline & $75.61 \%$ & $21.95 \%$ & $2.44 \%$ & & \\
\hline \multirow[t]{2}{*}{4 to $6.9 \mathrm{gm} / \mathrm{dl}$} & 1 & 0 & 0 & \multirow{2}{*}{1} & \multirow{2}{*}{0.81} \\
\hline & $0.00 \%$ & $0.00 \%$ & $0.00 \%$ & & \\
\hline
\end{tabular}

Table 4: Birth weight in $\mathrm{kg}$ ( $3^{\text {rd }}$ trimester $)$.

\begin{tabular}{|c|c|c|c|c|}
\hline$\geq 2.5 \mathrm{~kg}$ & $2-2.49 \mathrm{~kg}$ & $<2 \mathrm{~kg}$ & No. of pregnant women & $\%$ of pregnant women \\
\hline 27 & 8 & 2 & \multirow{2}{*}{37} & \multirow{2}{*}{33.94} \\
\hline $72.97 \%$ & $21.62 \%$ & $5.41 \%$ & & \\
\hline 24 & 4 & 3 & \multirow{2}{*}{31} & \multirow{2}{*}{28.44} \\
\hline $77.42 \%$ & $12.90 \%$ & $9.68 \%$ & & \\
\hline 27 & 10 & 2 & \multirow{2}{*}{39} & \multirow{2}{*}{35.78} \\
\hline $69.23 \%$ & $25.64 \%$ & $5.13 \%$ & & \\
\hline 2 & 0 & 0 & 2 & 1.83 \\
\hline
\end{tabular}

In $2^{\text {nd }}$ trimester analysis of birth weight of babies of women with normal $\mathrm{Hb}$ ( $\geq 11 \mathrm{gm} / \mathrm{dl}$ ) showed that $97.06 \%$ of women had given birth to babies with normal birth weight while $2.94 \%$ women had low birth weight babies $(2-2.49 \mathrm{~kg})$ and $0 \%$ women had very low birth weight babies ( $2 \mathrm{~kg}$ ). In $2^{\text {nd }}$ trimester analysis of birth weight of babies of women with mild anemia (Hb 10-10.9 gm/dl) showed that $80.85 \%$ pregnant women had given birth to babies with normal birth weight while $10.64 \%$ women had low birth weight babies and $8.51 \%$ women had very low birth weight babies. In $2^{\text {nd }}$ trimester analysis of birth weight of babies of women with moderate anaemia ( $\mathrm{Hb} 7-$ $9.9 \mathrm{gm} / \mathrm{dl}$ ) showed that $75.61 \%$ pregnant women with moderate anaemia had given birth to babies with normal birth weight while $21.95 \%$ women had low birth weight babies and $2.44 \%$ women had very low birth weight babies.

In $3^{\text {rd }}$ trimester analysis of birth weight of babies of women with normal $\mathrm{Hb}(\geq 11 \mathrm{gm} / \mathrm{dl})$ showed that $72.97 \%$ of women had given birth to babies with normal birth weight while $21.62 \%$ women had low birth weight babies (2-2.49 $\mathrm{kg})$ and $5.41 \%$ women had very low birth weight babies $(2$ $\mathrm{kg}$ ). In $3^{\text {rd }}$ trimester analysis of birth weight of babies of women with mild anemia ( $\mathrm{Hb} 10-10.9 \mathrm{gm} / \mathrm{dl})$ showed that $77.42 \%$ pregnant women with mild anemia had given birth to babies with normal birth weight while $12.90 \%$ women had low birth weight babies and $9.68 \%$ women had very low birth weight babies. In $3^{\text {rd }}$ trimester analysis of birth weight of babies of women with moderate anemia ( $\mathrm{Hb} 7$ $9.9 \mathrm{gm} / \mathrm{dl}$ ) showed that $69.23 \%$ pregnant women with moderate anemia had given birth to babies with normal birth weight while $25.64 \%$ women had low birth weight babies and $5.13 \%$ women had very low birth weight babies.

\section{DISCUSSION}

Prevalence of anemia in all the age groups is higher in India as compared to other developing countries. According to WHO, the prevalence of anemia in pregnancy globally is around $55.9 \%$. In India incidence of anemia in pregnancy has been noted as high as $33-89 \% .^{15}$

It increases the maternal morbidity, fetal and neonatal mortality and morbidity significantly with 7-10 million children born with low birth weight each year. Margaret Balfour was credited as the first to draw the attention of anemia in pregnancy in India. ${ }^{16}$ Levy et al for example, observed that maternal anemia was an independent risk factor for preterm delivery and low birth weight. ${ }^{17}$

Malhotra et al, observed that the mean birth weight was highest in babies with maternal hemoglobin concentration between 9.6 and $10.5 \mathrm{gm} \% .^{18}$

Maternal hematological status and risk of low birth weight and preterm delivery was studied in Patan Hospital, Kathmandu, Nepal. In this case-control study, 1400 pregnant women who attended the hospital for antenatal care and delivery in the period 1994 to 1996 were included. Severe anemia (hematocrit $\leq 24 \%$ ) was associated with a significantly increased risk of low birth weight $(<2500 \mathrm{gm})$ and preterm delivery ( $<37$ weeks gestation). ${ }^{19}$ In study of Nadia et al the newborn birth weight was affected by maternal anemia, out of 50 newborns 35 babies born to mothers with mild anemia had mean birth weight of $3.1 \mathrm{~kg}$, 
11 babies born to mothers with moderate anemia had mean birth weight of $2.7 \mathrm{~kg}$ and 4 babies born to mother with severe anemia the mean birth weight was $2.2 \mathrm{~kg} .{ }^{20}$ Steer and colleagues studied a large population of 153,602 pregnancies and reported that the lowest hemoglobin concentration during pregnancy $(85-105 \mathrm{gm} / \mathrm{l})$ is associated with maximum mean birth weight and the lowest incidences of LBW and preterm delivery. ${ }^{21,22}$

\section{CONCLUSION}

It has been seen in the study that maternal anemia is significantly associated with impact on birth weight. The major concern about the adverse effects of anemia on pregnant women is that there is a greater risk of perinatal mortality and morbidity. Babies who are undernourished in the womb face a greatly increased risk of dying during their early months and years. Those who survive have impaired immune function and an elevated risk of disease. Effort should be directed towards awareness of adolescents and women regarding prevention of anemia. Hemoglobin level needs to be checked in adolescent girls and women before pregnancy and anemia should be treated before they get married and become pregnant so that their pre pregnancy hemoglobin level is normal and babies born are of normal birth weight. This will contribute in building a healthy new generation.

\section{ACKNOWLEDGMENTS}

I am thankful to all the patients who co-operated for this study and all the seniors, colleagues and staff who helped in the study. I am especially thankful to Mr. Sourav Roy, Chief, CSR, Tata Steel for encouragement, Mr. Shahid Raza Jamali, Pathology Technician for data collection, data entry and Mr. Madhu Mangal Mandal, Pharmacist for data analysis.

\section{Funding: No funding sources}

Conflict of interest: None declared

Ethical approval: The study was approved by the Institutional Ethics Committee

\section{REFERENCES}

1. World Health Organization. Worldwide Prevalence of Anemia 1993-2005: A Global Database on Anemia. Available from: http://whqlibdoc.who.int/ publications/2008/9789241596657_eng.pdf.

Accessed on 12 December 2020.

2. Kidanto HL, Mogren I, Lindmark G, Massawe S, Nystrom L. Risks for preterm delivery and low birth weight are independently increased by severity of maternal anaemia. South Afr Med J. 2009;99(2):98102.

3. Gruenwald P. fetal Growth and Development. In: Corton MM, Leveno K, Bloom S, Hauth J, Rouse D, Spong C, eds. Williams Obstetrics. 23rd edn. McGraw Hill Professional; 2009.
4. Chandra S, Anil Kumar T. Anemia: a brief overview regards the pregnant state. J Womens Health Issues Care. 2014;3:1.

5. Gupta S. A text book of pediatrics for medical student, 4th Edition 2003,

6. Demmouche A, Lazrag A, Moulessehoul S. Prevalence of anaemia in pregnant women during the last trimester: consequence for birth weight. Eur Rev Med Pharmacol Sci. 2011;15(4):436-5.

7. Sumithra M. Maternal nutrition and low birth weight what is really important. Indian $\mathbf{J}$ Med Res. 2009;130:600-8.

8. Gupta KR. Care of low birth weight neonates. JK Sci. 2008;10(4).

9. Biswas R, Dasgupta A, Sinha RN, Chaudhuri RN. An epidemiological study of low birth weight newborns in the district of Puruliya, West Bengal. Indian $\mathbf{J}$ Public Health. 2008;52(2):65-71.

10. Steer PJ. Maternal Hemoglobin concentration and birth weight. Am J Clin Nutr. 2000;71(5):1285S-7S.

11. Shayamkaushik. A study on neonatal morbidity at Indira Gandhi Medical College, Simla, 2008.

12. Ramachandra N. Birthweight birthright. Mint. 2013. Available from: https://www.livemint.com/Opinion/ lznnDseEccQyqJ7oMLxt4L/Birthweight-

birthright.html. Accessed on 12 December 2020.

13. Demmouche A, Lazrag A, Moulessehoul S. Prevalence of anaemia in pregnant women during the last trimester: consequense for birth weight. Eur Rev Med Pharmacol Sci. 2011;15(4):436-5.

14. Afolabi BB, Akinola OI. What is the optimum maternal haemoglobin concentration level for a normal birth weight in Lagos? Trop J Obstet Gynaecol. 2004;21(1):4-6.

15. Muthayya S. Maternal nutrition \& low birth weightwhat is really important. Indian $\mathbf{J}$ Med Res. 2009;130(5):600-8.

16. Viveki RG, Halappanavar AB, Viveki PR, Halki SB, Maled VS, Deshpande PS. Prevalence of anaemia and its epidemiological determinants in pregnant women. Al Ameen J Med Sci. 2012;5(3):216-3.

17. Levy A, Fraser D, Katz M, Mazor M, Sheiner E. Maternal anemia during pregnancy is an independent risk factor for low birthweight and preterm delivery. Eur J Obstet Gynecol Reprod Biol. 2005;122(2):1826.

18. Malhotra M, Sharma JB, Batra S, Sharma S, Murthy NS, Arora R. Maternal and perinatal outcome in varying degrees of anemia. Int $\mathrm{J}$ Gynaecol Obstet. 2002;79(2):93-100.

19. Bondevik GT, Lie RT, Ulstein M, Kvåle G. Maternal hematological status and risk of low birth weight and preterm delivery in Nepal. Acta Obstet Gynecol Scand. 2001;80(5):402-8.

20. Al-Hilli NM. The effect of maternal anaemia on cord blood haemoglobin and newborn birth weight. Karbala J Med. 2010;2(8-9):13-9.

21. Passerini L, Casey GJ, Biggs BA, Cong DT, Phu LB, Phuc TQ, et al. Increased birth weight associated with regular pre-pregnancy deworming and weekly iron- 
folic acid supplementation for Vietnamese women. PLoS Neglect Trop Dis. 2012;6(4):e1608.

22. Whiltaker PG, Macphil S, Lind T. Serial hematological changes and pregnancy outcome. Obstet Gynaecol. 1996;88(1):33-9.
Cite this article as: Tiwari P. Relationship between maternal hemoglobin concentration during pregnancy and neonatal birth weight in urban poor community in and around Jamshedpur, Jharkhand, India. Int $\mathbf{J}$ Reprod Contracept Obstet Gynecol 2021;10:3828-33. 